\title{
Gender-Related Difference in Left Ventricular Diastolic Elastance During Exercise in Patients With Diabetes Mellitus
}

\author{
Jong-Won Ha, MD, PhD; Hyun-Chul Lee, MD, PhD*; Sungha Park, MD; \\ Eui-Young Choi, MD; Hye-Sun Seo, MD; Chi-Young Shim, MD; Jin-Mi Kim, RN; \\ Jeong-Ah Ahn, RN; Se-Wha Lee, RN; Se-Joong Rim, MD, PhD; \\ Jae K. Oh, MD, FACC**; Namsik Chung, MD, PhD
}

\begin{abstract}
Background Because the ratio of mitral inflow and annular velocity to stroke volume has been reported as an index of diastolic elastance (Ed), the hypothesis tested in the present study was that Ed during exercise would be more abnormal in female than in male patients with type 2 diabetes.

Methods and Results Ed was measured at rest and during graded supine bicycle exercise (25W, 3-min increments) in 53 patients ( 27 males, mean age $53 \pm 14$ years) with type 2 diabetes and 53 age- and gender-matched controls. The patients with diabetes were divided into 2 groups by gender. Ed was not significantly different at rest between men and women, but was significantly higher during exercise in women than in men $(25 \mathrm{~W}, 0.15 \pm 0.04$ vs $0.20 \pm 0.07, \mathrm{p}=0.009 ; 50 \mathrm{~W}, 0.16 \pm 0.05$ vs $0.21 \pm 0.08$, $\mathrm{p}=0.0175$ ).

Conclusion Left ventricular (LV) diastolic elastance is abnormal during exercise, but not at rest, in patients with diabetes without overt heart disease. Female gender was associated with increased LV stiffness during exercise among patients with type 2 diabetes. (Circ J 2008; 72: 1443-1448)
\end{abstract}

Key Words: Diabetes mellitus; Diastole; Exercise; Gender; Stiffness

D iabetes mellitus is an important cause of heart failure (HF). In clinical trials of HF the prevalence of diabetes ranges from $10 \%$ to more than $30 \%^{1}$ and the outcome of such patients with HF is worse than that of patients without diabetes. Interestingly, the risk of HF in diabetic patients is higher in women than in men, even after adjusting for other risk factors? Moreover, women with HF tend to experience more symptoms than men and the number of hospitalizations is higher among women than among men? It also has been shown that women with HF more often have preserved left ventricular (LV) systolic function. $^{4-6}$ Using the ratio of mitral inflow and annular velocities (E/E') over stroke volume (SV) as an index of diastolic elastance (Ed) has been reported ${ }^{7}$ and it offers advantages in examining the relationship between gender and Ed during exercise as well as at rest. We hypothesized that Ed during exercise would be more abnormal in women than in men among patients with type 2 diabetes.

(Received December 17, 2007; revised manuscript received April 23, 2008; accepted April 30, 2008)

Division of Cardiology, *Division of Endocrinology, Yonsei University College of Medicine, Seoul, Republic of Korea and **Division of Cardiovascular Diseases, Mayo Clinic College of Medicine, Rochester, $M N, U S A$

Conflict of interest: nothing to declare.

This study was presented in part at the Annual Scientific Sessions of American Heart Association, November, 2006, Chicago, IL, USA.

Mailing address: Jong-Won Ha, MD, PhD, Division of Cardiology, Yonsei University College of Medicine, 134 Shinchon-dong, Seodamungu, Seoul 120-752, Republic of Korea. E-mail: jwha@yuhs.ac All rights are reserved to the Japanese Circulation Society. For permissions, please e-mail: cj@j-circ.or.jp

\section{Methods}

\section{Study Population}

The study population comprised 53 patients (27 males, mean age $53 \pm 14$ years) with type 2 diabetes and 53 age- and gender-matched controls. The patients with diabetes had no symptoms or signs of heart disease, were in sinus rhythm and had a normal resting 12-lead ECG. Exclusion criteria were significant atrial or ventricular arrhythmia, significant valvular diseases ( $\geq$ moderate severity), significant coronary artery disease, prior history of myocardial infarction, depressed LV systolic function (ejection fraction $(\mathrm{EF})<50 \%$ ) or any regional wall motion abnormality, pericardial disease, and unable to exercise. The control subjects were considered to have a low probability of coronary artery disease on clinical grounds and had a normal exercise stress echocardiogram. Because this study's aim was to examine diabetes as an independent disease contributing to myocardial dysfunction, patients who had coexisting hypertension were excluded. Study approval was obtained from the Internal Review Board of Yonsei University College of Medicine.

\section{The 2-Dimensional (D) and Exercise Doppler Echocardiography (Diastolic Stress \\ Echocardiography $)^{8}$}

Standard 2-D measurements (LV diastolic and systolic dimensions, ventricular septum and posterior wall thickness, left atrial volume, LV outflow tract diameter) were obtained with the patient in the left lateral position. LVEF was calculated by the modified Quinones method? Left atrial volume was measured according to the modified biplane area-length method $!^{10,11}$ After obtaining the rest images in the standard parasternal and apical views, multistage supine 
Table 1 Comparison of Baseline Echocardiographic Findings in Patients With Diabetes Mellitus and the Control Subjects

\begin{tabular}{lccc}
\hline \hline & Diabetes $(n=53)$ & Control $(n=53)$ & $p$ value \\
\hline LVEDD $(\mathrm{mm})$ & $49 \pm 4$ & $49 \pm 5$ & 0.62 \\
LVESD $(\mathrm{mm})$ & $32 \pm 4$ & $32 \pm 5$ & 0.69 \\
Ejection fraction $(\%)$ & $66 \pm 7$ & $67 \pm 7$ & 0.64 \\
IVS $(\mathrm{mm})$ & $9 \pm 2$ & $9 \pm 2$ & 0.67 \\
PW $(\mathrm{mm})$ & $9 \pm 2$ & $9 \pm 2$ & 0.67 \\
LAVI $\left(\mathrm{ml} / \mathrm{m}^{2}\right)$ & $20 \pm 5$ & $22 \pm 9$ & 0.071 \\
E $(\mathrm{m} / \mathrm{s})$ & $0.67 \pm 0.13$ & $0.62 \pm 0.15$ & 0.12 \\
A $(\mathrm{m} / \mathrm{s})$ & $0.66 \pm 0.16$ & $0.66 \pm 0.19$ & 0.87 \\
E/A & $1.1 \pm 0.3$ & $1.0 \pm 0.4$ & 0.53 \\
DT $(\mathrm{ms})$ & $193 \pm 39$ & $202 \pm 44$ & 0.29 \\
TR velocity $(\mathrm{m} / \mathrm{s})$ & $2.1 \pm 0.3$ & $2.2 \pm 0.2$ & 0.18 \\
$E^{\prime}(\mathrm{cm} / \mathrm{s})$ & $6.6 \pm 2.1$ & $6.7 \pm 2.3$ & 0.73 \\
E/E' & $10.9 \pm 3.4$ & $9.7 \pm 2.5$ & 0.036 \\
$S^{\prime}(\mathrm{cm} / \mathrm{s})$ & $6.5 \pm 1.1$ & $6.8 \pm 1.1$ & 0.22 \\
\hline
\end{tabular}

LVEDD, left ventricular end-diastolic dimension; LVESD, left ventricular end-systolic dimension; IVS, interventricular septal thickness; PW, posterior wall thickness; LAVI, left atrial volume index; E, peak velocity of early diastolic filling; A, peak velocity of diastolic filling during atrial contraction; DT, deceleration time; TR, tricuspid regurgitation; E', early diastolic mitral annular velocity; $S$, systolic mitral annular velocity.

bicycle exercise testing was performed with a variable load bicycle ergometer (Medical Positioning, Inc, Kansas City, MO, USA). Patients pedaled at constant speed, beginning at a workload of $25 \mathrm{~W}$ with an increment of $25 \mathrm{~W}$ every $3 \mathrm{~min}$. Echocardiography was performed using a GE Vingmed System 7 ultrasound system with $2.5-\mathrm{MHz}$ transducer during rest, each stage of exercise, and during recovery. From the apical window, a 1-2-mm pulsed Doppler sample volume was placed at the mitral valve tip and mitral flow velocities from 5-10 cardiac cycles were recorded. The mitral inflow velocities were traced and the following variables were obtained: peak velocity of early (E) and late (A) filling, and deceleration time (DT) of the E-wave velocity. Tricuspid regurgitant (TR) jet velocity was also obtained to estimate pulmonary artery systolic pressure using continuous-wave Doppler, if measurable. SV was measured from the LV outflow tract diameter and the pulse wave Doppler signal as previously described $!^{2}$ Mitral annular velocity was measured by Doppler tissue imaging using the pulsed-wave mode. The filter was set to exclude high-frequency signals and the Nyquist limit was adjusted to a range of $15-20 \mathrm{~cm} / \mathrm{s}$. Gain and sample volume were minimized to allow for a clear tissue signal with minimal background noise. Early diastolic (E') and systolic (S') velocities of the mitral annulus were measured from the apical 4-chamber view with a 2- to 5-mm sample volume placed at the septal corner of the mitral annulus. To provide a continuous variable that might estimate $\mathrm{Ed}$, the E/E' ratio was used as an estimation of mean left atrial pressure ${ }^{13-15}$ Operant Ed was estimated as $\mathrm{E} / \mathrm{E}$ ' divided by the volume (SV) of filling during diastole, assuming the absence of significant aortic regurgitation? These measurements were performed at baseline, at each stage of exercise, and in recovery in the same sequence. All data were stored digitally and measurements were made at completion of each study. The 2-D echocardiographic images from the apical views at rest and during exercise were acquired, digitized, recorded and analyzed for the wallmotion analysis.

\section{Statistical Analysis}

Continuous variables were summarized as a mean \pm standard deviation. Categorical variables were summarized as a percentage of the group total. Unpaired Student's t-test and chi-squared analysis were used to compare continuous and categorical variables, respectively. Differences in hemodynamic variables and Doppler indices between rest and peak exercise were compared with repeated measures ANOVA. Statistical significance was defined as $<0.05$. Intraobserver variability was examined in a blinded fashion in 6 randomly selected subjects by measurement of LV diastolic parameters 3 times at each of 3 stages (ie, baseline, $25 \mathrm{~W}, 50 \mathrm{~W}$ ) of exercise echocardiography. Interobserver variability was assessed by comparing the mean values of the LV diastolic parameters measured by 2 experienced observers at each stage of exercise echocardiography. Intraclass correlation coefficients (ICC, r) were used to assess intraobserver variability using statistical software (version 13.0, SPSS Inc, Chicago, IL, USA). The calculation of ICC is ST2/(ST2+ $\mathrm{Se} 2$ ), where ST2 and Se2 are unbiased estimators of the components of variance caused by error-free variability among subjects and random error (within-subject variability), respectively. An ICC value $>0.75$ is considered excellent, $0.4-0.75$ fair to good, and $<0.4$ is poor. Interobserver variability was estimated using a paired t-test. Values of ICCs for agreement with LV diastolic parameters were excellent at the 3 stages of exercise echocardiography for both observers $(r>0.9)$. The values for the LV diastolic parameters measured by 2 observers were not significantly different $(\mathrm{p}=\mathrm{NS}$ ) at the 3 stages of exercise, showing high interobserver agreement except for DT at baseline and $25 \mathrm{~W}$ of exercise ( $\mathrm{p}=0.06, \mathrm{p}=0.01$, respectively).

\section{Results}

Comparison of Diabetic Patients and Control Subjects

Baseline echocardiographic findings of the patients with diabetes and control subjects are presented in Table 1. There were no significant differences between the groups in LV end-diastolic or end-systolic dimensions, wall thickness, left atrial volume index and $\mathrm{EF}$, nor in the mitral inflow velocities (E, A, E/A, DT). TR velocity was also similar between the groups. However, E/E' was higher in patients with diabetes than in control subjects. In both groups, heart rate and the systolic and diastolic blood pressures increased after exercise compared with rest. However, no significant differences were observed between the groups in the changes in heart rate or blood pressures at rest or during exercise. The magnitude of change in SV from rest to exercise did not dif- 
A

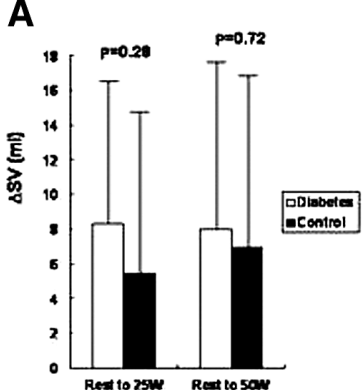

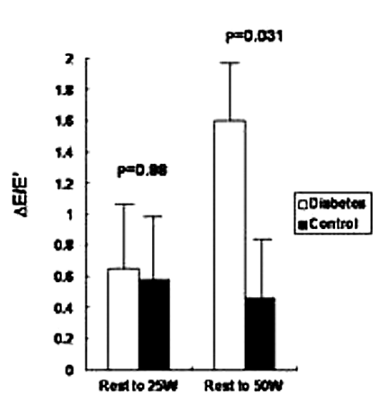

B

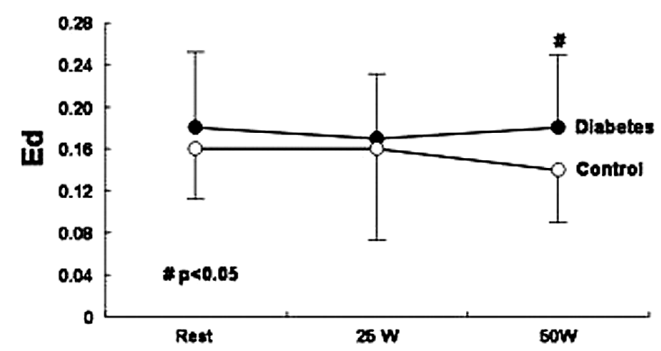

Fig 1. (A) Left panel: Magnitude of the change of stroke volume (SV) in subjects from resting to exercising. Similar SV changes from rest to exercise between patients with diabetes and control subjects. Right panel: Magnitude of change of ratio of early diastolic mitral flow velocity and annular velocity (E/E') values in subjects when at rest to when exercising. Note the significantly higher E/E' increment during exercise in patients with diabetes. (B) Changes in diastolic elastance (Ed) when at rest and during exercise. Similar Ed values were measured when the subjects were at rest and during mild exertion, but were significantly higher in patients with diabetes during moderate exercise.

Table 2 Clinical Characteristics of the Diabetic Patients

\begin{tabular}{lccc}
\hline \hline & Men $(n=27)$ & Women $(n=26)$ & p value \\
\hline Age (years) & $51.3 \pm 14.1$ & $55.2 \pm 13.3$ & 0.30 \\
Duration of diabetes (years) & $12.7 \pm 9.2$ & $12.5 \pm 7.7$ & 0.95 \\
Body mass index & $24.4 \pm 3.4$ & $23.4 \pm 2.7$ & 0.24 \\
Renal impairment & 1 & 1 & 0.96 \\
Retinopathy & 4 & 6 & 0.37 \\
Peripheral neuropathy & 4 & 6 & 0.37 \\
Blood glucose (mg/dl) & $151 \pm 50$ & $188 \pm 58$ & 0.066 \\
Hemoglobin Alc (\%) & $8.4 \pm 1.5$ & $8.2 \pm 1.4$ & 0.82 \\
Insulin & 8 & 8 & 0.85 \\
Metformin & 5 & 8 & 0.21 \\
Sulfonylurea & 8 & 9 & 0.58 \\
Thiazolidinediones & 4 & 3 & 0.74 \\
Exercise duration $(s)$ & $605 \pm 188$ & $407 \pm 136$ & $<0.0001$ \\
\hline
\end{tabular}

Table 3 Comparison of Baseline Echocardiographic Findings in the Men and Women With Diabetes

\begin{tabular}{lccl}
\hline \hline & Men $(n=27)$ & Women $(n=26)$ & $p$ value \\
\hline LVEDD $(\mathrm{mm})$ & $50 \pm 4$ & $47 \pm 4$ & 0.0164 \\
LVESD $(\mathrm{mm})$ & $33 \pm 4$ & $31 \pm 3$ & 0.0353 \\
Ejection fraction $(\%)$ & $65 \pm 9$ & $67 \pm 5$ & 0.34 \\
IVS $(\mathrm{mm})$ & $10 \pm 2$ & $9 \pm 1$ & 0.0086 \\
PW $(\mathrm{mm})$ & $10 \pm 2$ & $9 \pm 1$ & 0.0006 \\
LV mass index $\left(\mathrm{g} / \mathrm{m}^{2}\right)$ & $99.6 \pm 22.8$ & $87.6 \pm 15.6$ & 0.0513 \\
LAVI $\left(\mathrm{ml} / \mathrm{m}^{2}\right)$ & $19 \pm 5$ & $20 \pm 5$ & 0.68 \\
E $(\mathrm{m} / \mathrm{s})$ & $0.66 \pm 0.14$ & $0.70 \pm 0.15$ & 0.14 \\
A $(\mathrm{m} / \mathrm{s})$ & $0.68 \pm 0.17$ & $0.75 \pm 0.19$ & 0.062 \\
E/A & $1.0 \pm 0.4$ & $1.0 \pm 0.3$ & 0.26 \\
DT $(\mathrm{ms})$ & $206 \pm 51$ & $207 \pm 45$ & 0.89 \\
TR velocity $(\mathrm{m} / \mathrm{s})$ & $2.1 \pm 0.3$ & $2.3 \pm 0.4$ & 0.12 \\
Stroke volume $(\mathrm{ml})$ & $68 \pm 13$ & $63 \pm 14$ & 0.19 \\
$E^{\prime}(\mathrm{cm} / \mathrm{s})$ & $6.3 \pm 2.0$ & $6.0 \pm 2.2$ & 0.42 \\
E/E' & $11.0 \pm 3.3$ & $12.8 \pm 4.9$ & 0.055 \\
$S^{\prime}(\mathrm{cm} / \mathrm{s})$ & $7.2 \pm 1.7$ & $6.5 \pm 1.2$ & 0.051 \\
\hline
\end{tabular}

Abbreviations as in Table 1.

fer significantly between the patients with diabetes and the control subjects (from rest to $25 \mathrm{~W}: 8.3 \pm 9.6$ vs $5.4 \pm 9.8 \mathrm{ml}$, $\mathrm{p}=0.28$; from rest to $50 \mathrm{~W}: 8.0 \pm 9.6$ vs $7.0 \pm 10.0 \mathrm{ml}, \mathrm{p}=0.72$ ). However, in the patients with diabetes, the increase in E/E' from rest to $50 \mathrm{~W}$ of exercise was significantly higher than in the control subjects (from rest to $25 \mathrm{~W}$ : $0.65 \pm 0.34$ vs $0.58 \pm 0.36, \mathrm{p}=0.88$; from rest to $50 \mathrm{~W}: 1.6 \pm 0.37$ vs $0.46 \pm$ $0.37 \mathrm{ml}, \mathrm{p}=0.031$ ) (Fig 1A). At rest and during $25 \mathrm{~W}$ of exercise, Ed was not significantly different between the groups (rest: $0.18 \pm 0.07$ vs $0.16 \pm 0.05, \mathrm{p}=0.13 ; 25 \mathrm{~W}: 0.17 \pm 0.06$ vs $0.16 \pm 0.09, \mathrm{p}=0.63)$. However, during $50 \mathrm{~W}$ of exercise, Ed became significantly higher in patients with diabetes compared with control subjects $(50 \mathrm{~W}: 0.18 \pm 0.07$ vs $0.14 \pm$ $0.05 \mathrm{~cm} / \mathrm{s}, \mathrm{p}=0.048)($ Fig 1B).

\section{Comparison of Male and Female Patients With Diabetes} Mellitus (Table 2)

There were no significant differences between men and women regarding age, duration of diabetes, hemoglobin A1c, diabetic complications or the medications prescribed for 
Table 4 Comparison of the Hemodynamic Response to Exercise of the Men and Women With Diabetes

\begin{tabular}{lccc}
\hline \hline & Men $(n=27)$ & Women $(n=26)$ & p value \\
\hline HR at rest $($ beats $/ \mathrm{min})$ & $69 \pm 9$ & $66 \pm 7$ & 0.13 \\
HR at $25 \mathrm{~W}($ beats $/ \mathrm{min})$ & $93 \pm 7$ & $93 \pm 14$ & 0.97 \\
HR at $50 \mathrm{~W}($ beats $/ \mathrm{min})$ & $101 \pm 8$ & $109 \pm 20$ & 0.09 \\
Systolic $B P(\mathrm{mmHg})$ at rest & $117 \pm 17$ & $116 \pm 17$ & 0.74 \\
Systolic $B P(\mathrm{mmHg})$ at $25 \mathrm{~W}$ & $146 \pm 19$ & $146 \pm 24$ & 0.99 \\
Systolic $B P(\mathrm{mmHg})$ at $50 \mathrm{~W}$ & $158 \pm 23$ & $158 \pm 30$ & 0.99 \\
Diastolic $B P(\mathrm{mmHg})$ at rest & $70 \pm 9$ & $69 \pm 7$ & 0.64 \\
Diastolic $B P(\mathrm{mmHg})$ at $25 \mathrm{~W}$ & $82 \pm 9$ & $82 \pm 10$ & 0.86 \\
Diastolic $B P(\mathrm{mmHg})$ at $50 \mathrm{~W}$ & $87 \pm 9$ & $85 \pm 12$ & 0.57 \\
\hline
\end{tabular}

HR, heart rate; $B P$, blood pressure; $W$, watts.

A

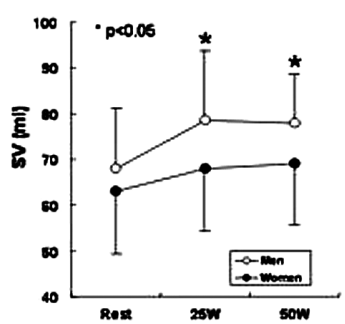

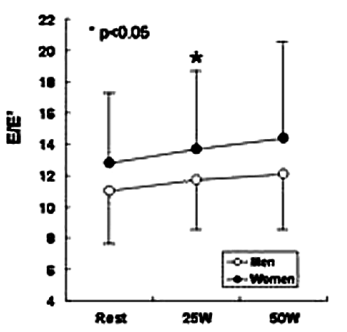

B
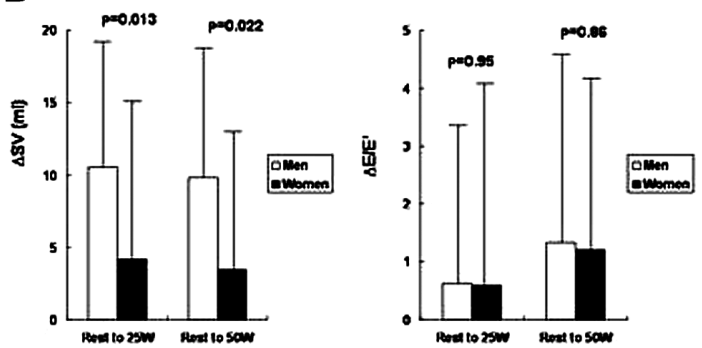

C

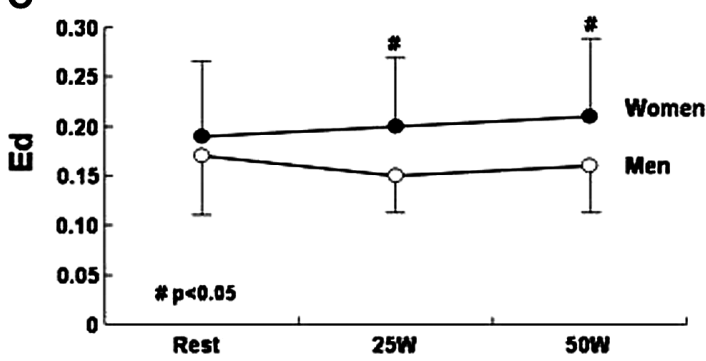

Fig 2. (A) Left panel: Change of SV in subjects when at rest to when exercising. Note the similar SV values at rest, but significantly smaller SV during exercise in women. Right panel: Change of E/E' values in subjects when at rest to when exercising. Similar E/E' values at rest and during exercise between men and women except during $25 \mathrm{~W}$ of exercise. (B) Left panel: Magnitude of change of SV in subjects when at rest to when exercising. Note significantly smaller SV increment during exercise in women. Right panel: The magnitude of change of E/E' values in subjects when at rest to when exercising. Similar E/E' changes from rest to exercise between men and women. (C) Ed value changes when at rest and during exercise. Similar Ed values were measured when the subjects were at rest, but were significantly higher in women during exercise. Abbreviations as in Fig 1.

diabetic treatment. However, exercise duration was significantly shorter in women than in of men $(605 \pm 188$ vs $407 \pm$ $136 \mathrm{~s}, \mathrm{p}<0.0001)$. When comparing the serum hemoglobin and creatinine levels of the men and women with diabetes, both were significantly higher in men than in women (serum creatinine: $1.05 \pm 0.27$ vs $0.82 \pm 0.21, \mathrm{p}=0.0009$; hemoglobin: $14.2 \pm 1.3$ vs $12.5 \pm 1.1, \mathrm{p}<0.0001)$. However, the range of serum creatinine was within normal in both genders. In $22(54 \%)$ of 41 women, exercise was limited primarily by leg fatigue, whereas dyspnea was the primary reason for stopping exercise in 10 . In men, leg fatigue was the main reason for stopping exercise in 32 and dyspnea was the main reason in 7 . There were no regional wall motion abnormalities either at rest or during exercise in either group. Table 3 shows the comparison of the echocardiographic findings in the 2 groups. Women with diabetes had a smaller LV cavity, and men had a thicker myocardium. However, at rest, there were no significant differences in left atrial volume index, mitral inflow velocities (E, A, E/A, DT), TR velocity, SV, S' or E' between the 2 groups. The effect of supine bicycle exercise on heart rate and blood pressures is shown in Table 4. In both groups, heart rate, systolic blood pressure and diastolic blood pressure increased after exercise compared with rest. There were no significant differences in the changes of systolic and diastolic blood pressures and heart rate at rest or during exercise between the groups, except for heart rate at $50 \mathrm{~W}$, which was significantly higher in women (Table 4). At rest, E/E' tended to be higher in women than in men, with borderline significance $(11.0 \pm 3.3$ vs $12.8 \pm 4.9, \mathrm{p}=0.055)$. However, during $25 \mathrm{~W}$ of exercise, $\mathrm{E} / \mathrm{E}$ ' became significantly higher in women compared with men $(11.7 \pm 3.2$ vs $13.7 \pm 5.2$, $\mathrm{p}=0.048)$. However, this difference was lost during $50 \mathrm{~W}$ of exercise $(12.1 \pm 3.4$ vs $14.4 \pm$ $6.2, \mathrm{p}=0.11)(\mathrm{Fig} 2 \mathrm{~A})$. The magnitude of the change in $\mathrm{E} / \mathrm{E}$ ' from rest to exercise did not differ significantly between the groups (from rest to $25 \mathrm{~W}$ : $0.6 \pm 2.8$ vs $0.6 \pm 3.6, \mathrm{p}=0.95$; from rest to $50 \mathrm{~W}: 1.3 \pm 3.4$ vs $1.2 \pm 3.0, \mathrm{p}=0.86$ ) (Fig 2B). In contrast to the increase in SV during a low level of exercise followed by a plateau observed in men, a blunted SV response was observed in women (Fig $2 \mathrm{~A})$. In women, the 
increase in SV from rest to exercise was significantly smaller compared with that in the men (from rest to $25 \mathrm{~W}$ : $10.5 \pm 8.7$ vs $4.2 \pm 8.8 \mathrm{ml}, \mathrm{p}=0.013$; from rest to $50 \mathrm{~W}: 9.8 \pm 8.4$ vs $3.4 \pm 9.3 \mathrm{ml}, \mathrm{p}=0.022$ ) (Fig $2 \mathrm{~B}$ ). At rest, Ed was not significantly different between the groups. However, during exercise, Ed became significantly higher in women compared with men $(25 \mathrm{~W}: 0.15 \pm 0.04$ vs $0.20 \pm 0.07, \mathrm{p}=0.009 ; 50 \mathrm{~W}$ : $0.16 \pm 0.05$ vs $0.21 \pm 0.08, \mathrm{p}=0.0175)$ (Fig $2 \mathrm{C})$. The gender difference in Ed during exercise was driven by the higher E/E' and significantly smaller SV increase during exercise in women. When we compared the Ed of female subjects with and without diabetes, it was similar at rest $(0.17 \pm 0.05$ vs $0.19 \pm 0.07, \mathrm{p}=0.09)$ and during $25 \mathrm{~W}$ of exercise $(0.17 \pm$ 0.08 vs $0.19 \pm 0.07, \mathrm{p}=0.14)$. However, Ed is significantly higher during $50 \mathrm{~W}$ of exercise $(0.15 \pm 0.04$ vs $0.21 \pm 0.08$, $\mathrm{p}=0.004$ ).

\section{Discussion}

The present study is, to our knowledge, the first to use the non-invasively-determined LV elastance to demonstrate a dynamic change in the ventricular stiffness of patients with type 2 diabetes. Interestingly, LV elastance at rest and during mild exertion did not differ between the patients with diabetes and the control subjects, but LV elastance became abnormal in diabetic patients during moderate exertion. More interestingly, another novel finding was that the noninvasively determined LV diastolic elastance during exercise differed among male and female patients with type 2 diabetes; LV diastolic elastance at rest did not differ between men and women, but became more abnormal in women even with mild exertion. Changes in SV and E/E' (ie, LV filling pressure) showed different patterns; the changes in E/E' was more prominent between patients with diabetes and control subjects, whereas the changes in SV during exercise were more marked between men and women with diabetes (Fig 3). These data suggest that the smaller ventricle with underlying myocardial abnormalities in diabetic women may lead to an increase in ventricular stiffness during exercise.

\section{Gender Difference of HF in Patients With Diabetes}

Previous investigations have shown higher rates of $\mathrm{HF}$ in women, despite higher EF, than in men after myocardial infarction! 6,17 The risk of HF in diabetic patients is also higher in women, and women with HF tend to experience more symptoms and more hospitalizations than men1,3 In addition, exercise intolerance and $\mathrm{HF}$ with preserved $\mathrm{EF}$ are also common in females, but little is known of the mechanism underlying the gender difference in the risk of HF in patients with diabetes. In animal studies it has been shown that females show less pathologic remodeling and dilatation ${ }^{18}$ Although previous studies have consistently shown a smaller LV in women, it does not draw much attention. HF with preserved EF is more common in the elderly, as well as in women. Several studies have found that approximately $5 \%$ decrease in the LV internal diastolic and systolic dimensions with age ${ }^{19-21}$ Women and the elderly, both of whom commonly have HF with preserved EF, have a relatively smaller ventricle. In contrast, athletes usually have a larger ventricle because regular training causes the heart to enlarge. In addition, despite the LV cavity enlargement and hypertrophy, LV systolic and diastolic function in athletes is usually normal. It has been suggested that the changes in LV size have implications for diastolic LV filling. It can be

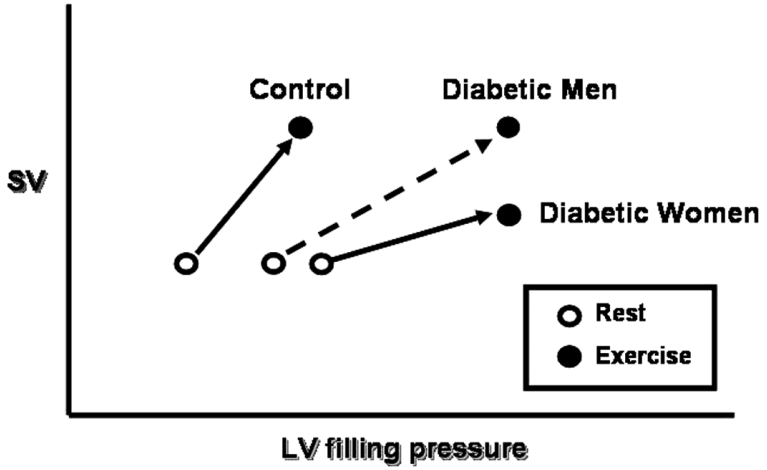

Fig 3. Schematic of SV vs left ventricular (LV) filling pressure, indicating the different directional changes from rest to exercise between control subjects and diabetic patients, and between men and women with diabetes. Changes in E/E' were more prominent than those of SV between patients with diabetes and control subjects, whereas the changes in SV during exercise were more marked between men and women with diabetes. Other abbreviations as in Fig 1.

speculated that a smaller LV cavity would be associated with abnormal LV chamber function despite preserved myocardial function. If myocardial function becomes abnormal in subjects with a small LV cavity, symptoms and signs of $\mathrm{HF}$ may develop despite normal EF, which is the case in the elderly. Although it is unclear in women, a recent investigation has demonstrated that cellular remodeling is different in women than in men after myocardial infarction. ${ }^{18}$ These findings underscore the importance of LV cavity size, as well as myocardial function, in the development of HF with preserved EF and, partly, the gender difference in the incidence and symptoms of HF. We believe that a smaller ventricle and/or underlying myocardial abnormality in diabetic women lowers the threshold for the development of symptoms and signs of HF despite having a normal EF.

\section{Hemodynamic Changes During Exercise}

During exercise in normal subjects, SV increases by approximately $20 \%$, with a concomitant reduction in endsystolic volume. The most remarkable physiologic aspect of the heart's ability to increase cardiac output with exercise is related to the multifold increase in diastolic filling rate mandated by the disproportionately shortened diastole during tachycardia. A recent investigation using tissue Doppler imaging has shown that the untwisting rate and intraventricular pressure gradient rise in concert almost 3-fold during exercise, which significantly augments transmitral flow. However, in patients with myocardial disease, such as hypertrophic cardiomyopathy, both the untwisting and intraventricular pressure gradient are dramatically blunted with exercise.22 It has been shown that in patients with HF and preserved LV EF, which is common in women with diabetes, exercise testing reveals the failure of SV increase with exercise, despite markedly elevated filling pressures. Kitzman et $\mathrm{al}^{23}$ used invasive cardiopulmonary exercise testing to study 7 patients who presented with HF and normal EF, and they showed a striking increase in pulmonary capillary wedge pressure in patients with HF compared with healthy subjects. In addition, although SV was not different at rest in the healthy subjects and patients with diastolic dysfunction, patients with diastolic dysfunction were unable to increase SV during exercise, whereas healthy subjects increased it by $25-40 \%$, which is quite similar to 
our results from the present study in which SV and filling pressures were measured non-invasively.

\section{Previous Investigations of Ed}

Although the LV pressure-volume loop is the ideal for assessing $\mathrm{LV}$ performance at rest and during exercise, it is not practical. A previous community-based analysis has addressed the impact of gender on Ed, showing higher values in women at rest compared with men? Our study further evaluated the impact of gender on Ed at rest as well as during exercise in patients with diabetes and showed that Ed at rest did not differ between men and women, but that LV elastance became abnormal in diabetic women even with mild exertion. Because early detection and treatment of subclinical ventricular dysfunction is suggested as an effective strategy to prevent or delay the onset of HF, the detection of preclinical ventricular dysfunction is mandatory in diabetic patients. We believe the results of our study extend the important concept of Ed, especially during exercise in patients with diabetes, and may help to better understand the pathophysiology of HF in diabetes and the gender difference in the incidence of $\mathrm{HF}$ in these patients.

\section{Study Limitations}

We could not exclude the effects of coronary microvascular disease. It has been suggested that microvascular disease, which is common in patients with diabetes, leading to reduced coronary flow reserve with angiographically normal coronary arteries is associated with a supernormal LV function during exercise ${ }^{24}$ Although none of the patients developed either exercise-induced myocardial ischemia on ECG or a wall motion abnormality, the potential influence of coronary microvascular disease can not be excluded. There were technical challenges in measuring E' when the heart rate increased; however, it has been shown that the E/E' ratio can be measured and used to estimate pulmonary artery wedge pressure with reasonable accuracy in sinus tachycardia. 5

\section{Conclusion}

LV diastolic stiffness is abnormal during exercise, but not at rest, in patients with diabetes without overt heart disease. Female gender was associated with a greater increase in LV stiffness during exercise in patients with type 2 diabetes.

\section{Acknowledgments}

This work was supported by the Korea Science and Engineering Foundation (KOSEF) grant funded by the Korea government (M1064212000106N4212-00110) and a Yonsei University Research Fund of 2006.

\section{References}

1. McMurray J, McDonagh T, Morrison CE, Dargie HJ. Trends in hospitalization for heart failure in Scotland 1980-1990. Eur Heart J 1993; 14: $1158-1162$.

2. Shindler DM, Kostis JB, Yusuf S, Quinones MA, Pitt B, Stewart D, et al. Diabetes mellitus, a predictor of morbidity and mortality in the Studies of Left Ventricular Dysfunction (SOLVD) Trials and Registry. Am J Cardiol 1996; 77: 1017-1020.

3. Petrie MC, Dawson NF, Murdoch DR, Davie AP, McMurray JJ. Failure of women's hearts. Circulation 1999; 99: 2334-2341.

4. Vasan RS, Larson MG, Benjamin EJ, Evans JC, Reiss CK, Levy D. Congestive heart failure in subjects with normal versus reduced left ventricular ejection fraction: Prevalence and mortality in a population-based cohort. J Am Coll Cardiol 1999; 33: 1948-1955.

5. Komajda M, Follath F, Swedberg K, Cleland J, Aguilar JC, Cohen-
Solal A, et al, Study Group on Diagnosis of the Working Group on Heart Failure of the European Society of Cardiology. The EuroHeart Failure Survey programme: A survey on the quality of care among patients with heart failure in Europe. Part 2: Treatment. Eur Heart $J$ 2003; 24: 464-474.

6. Klapholz M, Maurer M, Lowe AM, Messineo F, Meisner JS, Mitchell $\mathrm{J}$, et al, Consortium NYHF. Hospitalization for heart failure in the presence of a normal left ventricular ejection fraction: Results of the New York Heart Failure Registry. J Am Coll Cardiol 2004; 43: $1432-1438$.

7. Redfield MM, Jacobsen SJ, Borlaug BA, Rodeheffer RJ, Kass DA. Age- and gender-related ventricular-vascular stiffening: A community-based study. Circulation 2005; 112: 2254-2262.

8. Ha JW, Oh JK, Pellikka PA, Ommen SR, Stussy VL, Bailey KR, et al. Diastolic stress echocardiography: A novel noninvasive diagnostic test for diastolic dysfunction using supine bicycle exercise Doppler echocardiography. J Am Soc Echocardiogr 2005; 18: 63-68.

9. Quinones MA, Waggoner AD, Reduto LA. A new, simplified and accurate method for determining ejection fraction with two-dimensional echocardiography. Circulation 1981; 64: 744-753.

10. Ren JF, Kotler MN, DePace NL. Two-dimensional echocardiographic determination of left atrial emptying volume: A noninvasive index in quantifying the degree of nonrheumatic mitral regurgitation. $J$ Am Coll Cardiol 1983; 2: 729-736.

11. Appleton CP, Galloway JM, Gonzalez MS, Gaballa M, Basnight MA. Estimation of left ventricular filling pressures using two-dimensional and Doppler echocardiography in adult patients with cardiac disease: Additional value of analyzing left atrial size, left atrial ejection fraction and the difference in duration of pulmonary venous and mitral flow velocity at atrial contraction. J Am Coll Cardiol 1993; 22: $1972-1982$.

12. Oh JK, Seward JB, Tajik AJ. The echo manual, 2nd edn. Philadelphia; Lippincott Williams \& Wilkins; 1999.

13. Ommen SR, Nishimura RA, Appleton CP, Miller FA, Oh JK, Redfield MM, et al. Clinical utility of Doppler echocardiography and tissue Doppler imaging in the estimation of left ventricular filling pressures: A comparative simultaneous Doppler-catheterization study. Circulation 2000; 102: 1788-1794.

14. Sohn DW, Chai IH, Lee DJ, Kim HC, Kim HS, Oh BH, et al. Assessment of mitral annulus velocity by Doppler tissue imaging in the evaluation of left ventricular diastolic function. $J$ Am Coll Cardiol 1997; 30: 474-480.

15. Dokainish H, Zoghbi WA, Lakkis NM, Al-Bakshy F, Dhir M, Quinones MA, et al. Optimal noninvasive assessment of left ventricular filling pressures: A comparison of tissue Doppler echocardiography and B-type natriuretic peptide in patients with pulmonary artery catheters. Circulation 2004; 109: 2432-2439.

16. Tofler GH, Stone PH, Muller JE, Willich SN, Davis VG, Poole WK, et al. Effects of gender and race on prognosis after myocardial infarction: Adverse prognosis for women, particularly black women. $J \mathrm{Am}$ Coll Cardiol 1987; 9: 473-482.

17. Mendes LA, Davidoff R, Cupples LA, Ryan TJ, Jacobs AK. Congestive heart failure in patients with coronary artery disease: The gender paradox. Am Heart J 1997; 134: 207-212.

18. Crabbe DL, Dipla K, Ambati S, Zafeiridis A, Gaughan JP, Houser SR, et al. Gender differences in post-infarction hypertrophy in endstage failing hearts. J Am Coll Cardiol 2003; 41: 300-306.

19. Gardin JM, Henry WL, Savage DD, Ware JH, Burn C, Borer JS. Echocardiographic measurements in normal subjects: Evaluation of an adult population without clinically apparent heart disease. J Clin Ultrasound 1979; 7: 439-447.

20. Kitzman DW, Edwards WD. Age-related changes in the anatomy of the normal human heart. J Gerontol 1990; 45: M33-M39.

21. Klein AL, Burstow DJ, Tajik AJ, Zachariah PK, Bailey KR, Seward JB. Effects of age on left ventricular dimensions and filling dynamics in 117 normal persons. Mayo Clin Proc 1994; 69: 212-224.

22. Notomi Y, Martin-Miklovic MG, Oryszak SJ, Shiota T, Deserranno D, Popovic ZB, et al. Enhanced ventricular untwisting during exercise: A mechanistic manifestation of elastic recoil described by Doppler tissue imaging. Circulation 2006; 113: 2524-2533.

23. Kitzman DW, Higginbotham MB, Cobb FR, Sheikh KH, Sullivan MJ. Exercise intolerance in patients with heart failure and preserved left ventricular systolic function: Failure of the Frank-Starling mechanism. J Am Coll Cardiol 1991; 17: 1065-1072.

24. Picano E, Palinkas A, Amyot R. Diagnosis of myocardial ischemia in hypertensive patients. J Hypertens 2001; 19: 1177-1183.

25. Nagueh SF, Mikati I, Kopelen HA, Middleton KJ, Quinones MA, Zoghbi WA. Doppler estimation of left ventricular filling pressure in sinus tachycardia: A new application of tissue Doppler imaging. Circulation 1998; 98: 1644-1650. 